DOI: https://doi.org/10.47405/mjssh.v5i12.596

\begin{tabular}{|c|c|}
\hline The & Malaysian Journal of Social Sciences and Humanities (MJSSH) \\
\hline Malaysian Journal of & Volume 5, Issue 12, December 2020 \\
\hline (MJ-ssH) & e-ISSN : 2504-8562 \\
\hline & $\begin{array}{l}\text { Journal home page: } \\
\text { www.msocialsciences.com }\end{array}$ \\
\hline
\end{tabular}

\title{
Kepesatan Pembangunan dan Pemodenan Angkatan Tentera Malaysia (ATM) di Era Perang Dingin dan Pasca Perang Dingin
}

\author{
Ahmad Shah Pakeer Mohamed', Nazariah Osman', Mohamad Faisol Keling1 \\ ${ }^{1}$ College of Law, Government and International Studies, Universiti Utara Malaysia (UUM) \\ Correspondence: Ahmad Shah Pakeer Mohamed (ahmad7243@uitm.edu.my)
}

\begin{abstract}
Abstrak
"Fenomena anarki" telah mempengaruhi kebanyakan negara untuk memberikan tumpuan dan perhatian terhadap pembangunan Angkatan ketenteraan bagi menjamin keselamatan untuk tujuan kelangsungan hidup. Manakala merujukkan kepada teori neo-realisme, teori ini mengatakan dilema keselamatan sebagai situasi yang sentiasa ada ancaman yang cuba untuk menggugat keselamatan negara mahupun ianya dari bentuk unsur ancaman tradisional mahupun dari unsur dari ancaman bukan dari tradisional. Akibat dari senario keselamatan dan sifat anarki dalam sistem antarabangsa, keadaan ini akan menyebabkan negara perlu bergantung pada diri sendiri untuk kelangsungan hidup. Ini merujuk kepada konsep self help atau self reliance di mana setiap negara mempunyai kepentingan negara mereka tersendiri dalam meneruskan kelangsungan hidup dalam sistem antarabangsa. Melihat dari sudut Angkatan Tentera Malaysia (ATM,) perspektif pembangunan dan pemodenan ATM semasa era Perang Dingin dan Pasca Perang Dingin ternyata mempunyai perubahan yang signifikan di mana pembangunan ATM sebelum tahun 1990 lebih bersifat konvensional dan pasca Perang Dingin memperlihatkan pembangunan ATM bersifat lebih strategik.
\end{abstract}

Kata kunci: pemodenan, Angkatan Tentera Malaysia (ATM), perang dingin

\section{The Rapid Development and Modernization of the Malaysian Armed Forces (ATM) in the Cold War and Post-Cold War Era}

\begin{abstract}
The "phenomenon of anarchy" has influenced most countries to focus on the development of the Armed Forces to ensure security for the purpose of survival. While referring to the theory of neorealism, this theory says the security dilemma as a situation where there is always a threat that tries to threaten national security whether it is from the form of traditional threat elements or from elements of non-traditional threats. As a result of the security scenario and the nature of anarchy in the international system, this situation will cause the country to have to depend on itself for survival. This refers to the concept of self help or self reliance where each country has its own national interest in continuing survival in the international system. Looking at it from the ATM point of view, the perspective of the development and modernization of ATM during the Cold War and Post-Cold War era had significant changes where the development of ATM before 1990 was more to conventional and post-Cold War showed the development of ATM more strategic.
\end{abstract}

Keywords: modernization, Malaysian Armed Forces (ATM), cold war 


\section{Pengenalan}

Setelah berakhirnya Perang Dingin apabila runtuhnya tembok Berlin pada 1989 telah sememangnya mengubah landskap kajian bidang keselamatan dan ketenteraan. Ancaman konvensional sudah tidak menjadi ancaman yang utama lagi dan dunia kini terus membentuk ancaman-ancaman baru yang akhirnya memberi kesan langsung terhadap keselamatan sesebuah negara. Berakhirnya Perang Dingin dengan kesan dari globalisasi telah juga memberi kesan kepada peralihan dari sudut ancaman keselamatan iaitu dari ancaman ketenteraan kepada ancaman bukan berunsur ketenteraan "new threats". Landskap ini sudah pasti akan mengubah corak serta sistem keselamatan negara bagi menjaga kelangsungan kedaulatan sesebuah negara. Ketika dunia dilanda dengan Perang Dingin, penggunaan kuasa dari dua buah negara kuasa terbesar dunia iaitu Amerika Syarikat (AS) dan Kesatuan Soviet (USSR) telah merubah landskap kedudukan kuasa dunia menjadi bipolar. ${ }^{1}$ Keadaan ini menyebabkan penggunaan kuasa ketenteraan yang bercorakkan kekerasan (use of force) di kalangan dua buah negara yang digelar 'superpower' ini lebih berbentuk proxy dan keadaan ini menyebabkan perkembangan pembangunan pertahanan bukan sahaja hanya bertumpu kepada dua buah negara ini sahaja tetapi negara-negara "proxy" serta yang mempunyai pakatan dan kepentingan juga telah dibangunkan landskap serta sistem ketenteraannya. ${ }^{2}$

Merujuk kepada artikel penulisan Faisol (2016), beliau telah menyatakan bahawa Perang Dingin yang telah berakhir, membawa kepada zaman baharu di dalam geopolitik luar negara. Kejatuhan Kesatuan Soviet (USSR) telah menyebabkan sistem antarabangsa berubah dari sistem bipolar (1945-1990) kepada sistem unipolar yang bersifat hegemoni yang didominasi kuasa dari negara Amerika Syarikat. "Dengan ini, sistem geopolitik antarabangsa akan menjadi lebih mencabar dengan kemunculan kuasa-kuasa baru yang terdiri dari aspek politik, ekonomi juga ketenteraan. Sebagai contoh krisiskrisis yang berlaku seperti di rantau Asia Selatan dengan isu kuasa melibatkan India dan Pakistan, manakala di rantau Asia Timur krisis yang melibatkan China, Jepun dan Korea Utara, serta di Eropah dan sebagainya." Setiap negara di dunia terpaksa menghadapi perubahan serta cabaran yang berlaku dalam geopolitik antarabangsa dan dalam masa yang sama ia juga akan memberikan pengaruh yang kuat dalam pembentukan dasar politik, ekonomi dan juga keselamatan. ${ }^{3}$

Pemodenan atau modenisasi Angkatan Tentera Malaysia (ATM) merupakan antara gerakkan awal bagi negara untuk mentransformasikan sesebuah pasukan Angkatan ATM bagi menjadikan sebuah pasukan yang seimbang, sangat berwibawa, bersepadu dan sentiasa bersedia dalam menghadapi cabaran dalam sebarang konflik yang hadir. Dengan membuat pembelian beberapa aset untuk memantapkan cabangcabang di dalam sektor perkhidmatan ATM juga dilihat sangat tepat dan ianya adalah sebagai salah satu tanda aras dalam menyelaraskan hasrat ATM bagi menjadikan ATM sebagai salah satu organisasi yang cekap dan sentiasa dalam keadaan siap siaga. Walaupun begitu, sektor-sektor yang lain dalam unit-unit ketenteraan juga perlu diberikan perhatian serta dibangunkan dan ditingkatkan agar ia selari dan sentiasa relevan demi menjaga keselamatan negara. ${ }^{4}$ Merujuk kepada Dato Sri Najib Tun Razak (2006) (DSN), beliau menyatakan ATM sentiasa komited dan bersedia di dalam melaksanakan tanggungjawab, amanah serta peranannya sebagai benteng terakhir negara. ATM bukan hanya memfokuskan kepada pembelian aset untuk kegunaan ketenteraan yang bersifat canggih semata-mata. ${ }^{5}$ Asas-asas lain juga dilihat sangat penting seperti industri pertahanan (DI), pembangunan sumber yang sangat optimum, serta penglibatan luar negara atau kerjasama dengan kuasa-kuasa besar dunia. Kerjasama serantau juga dilihat sangat penting membantu negaranya untuk sentiasa bersiap sedia

\footnotetext{
${ }^{1}$ Datuk Dr Abdul Latiff Ahmad, Timbalan Menteri Pertahanan (2009). Teks Rasmi Ucapan Timbalan Menteri Pertahanan Sempena Lawatan Kerja Ke Kem Sri Pantai, Mersing pada 26 Julai 2009. hlm 18-19

${ }^{2}$ Burchill, S., \& Linklater, A. (1996). Theories of international relations. New York: St. Martin's Press.

${ }^{3}$ Keling, M. F., Mohamad, M. H., \& Abdul Batau, M. F. (2016). Faktor dan Proses Pembangunan Dasar Pertahanan Negara Malaysia. Malaysian Journal of Social Sciences and Humanities (MJSSH), 1(3), 31 41. Retrieved from https://msocialsciences.com/index.php/mjssh/article/view/16

${ }^{4}$ Noraini Zulkifli (2016), Kepentingan Na sional Jepun Di Selat Melaka: Kerangka Teori Dan Konseptual. Sumber diekses dari https://www.researchgate.net/publication/326987998 Teori_Realisme dan Neo Realismepdf

${ }^{5}$ Dato' Sri Mohd Najib Tun Abdul Razak (2006). semasa ucapan Penggulungan Bajet 2007 di Peringkat Dasar di Dewan Rakyat. http://www.pmo.gov.my/ucapan/?m=p\&p=najibtpm\&id=3587
} 
mempertahankan lokasi strategik dan memelihara keselamatan negara berasaskan kepada prinsipprinsip peningkatan keupayaan berdikari, pertahanan menyeluruh, diplomasi serta kerjasama serantau serta permodenan Angkatan tentera. ${ }^{6}$

Merujuk kepada Ananthan (2017), beliau mengatakan bajet merupakan perkara yg penting juga dalam memodenkan ATM. Peruntukan bajet negara juga akan memberi kesan untuk perbelanjaan operasi serta program pembangunan ketenteraan dan ia boleh memberikan petunjuk yang secara dasar tentang bagaimana negara mahu membentuk struktur kekuatan ketenteraannya. Jika peruntukan bajet dipotong, maka ia akan memberi kesan kepada pembangunan ATM dan ATM tidak dapat membentuk kekuatan untuk pemodenan Angkatan tentera. ${ }^{7}$ Menurut Mohamad Sabu (2019), beliau menyatakan pendekatan yang sama mengenai peruntukan bajet pertahanan negara. Menurut beliau, bajet merupakan elemen yang penting di dalam membangunkan dan memodenkan angkatan tentera. Pentingnya peruntukan yang besar perlu disalurkan dalam ATM untuk menjaga sistem pertahanan negara. Walaupun dilihat negara Malaysia kini dilihat dalam keadaan tenteram dan aman, namun peruntukan bajet untuk tujuan menjaga kepentingan negara adalah perlu kerana usaha memartabatkan kekuatan dan peranan tentera perlu sentiasa dilaksanakan dari semasa ke semasa bukan hanya bila ada ancaman yang datang baru negara hendak membangunkan ATM. ${ }^{8}$

Pembangunan dari sudut logistik pertahanan juga adalah merupakan elemen yang utama dalam memodenkan serta membangunkan ATM selain daripada kepentingan bajet pertahanan. Mantan Timbalan Menteri Pertahanan iaitu Datuk Seri Mohd Johari Baharum (2017) pernah menyatakan bahawa Datuk Seri Najib Tun Razak (DSN) semasa pentadbirannya, kerajaan sentiasa akan mengambil inisiatif untuk meningkatkan keupayaan ATM dari segi pembangunan dan pembelian aset serta pelbagai pengetahuan baharu di dalam industri pertahanan negara. Ia sangat bersesuaian dengan perkembangan teknologi industri pertahanan (DI) yang dilihat kini semakin canggih. Negara juga dilihat tidak ketinggalan dalam usaha untuk meningkatkan industri pertahanan agar sentiasa kompetitif dan berdaya saing dengan negara-negara lain khususnya di dalam rantau Asia Tenggara. ${ }^{9}$ Setiap aspek di dalam dasar pertahanan negara ini adalah merupakan asas yang penting untuk pengkaji melihat dengan lebih kritis sejauh mana pemodenan pertahanan yang telah dilaksanakan oleh ATM dari dahulu sehingga hari ini (Rajah 1).

Melihat kepada DPN yang telah dihasilkan oleh negara Malaysia, dasar pertahanan telah dibahagikan kepada enam aspek utama untuk menerangkan peranan dan dasar kerajaan menerusi enam aspek utama dalam membangunkan dan memodenkan sistem pertahanan negara. Aspek-aspek tersebut adalah pendekatan dasar pertahanan negara, strategi pertahanan, logistik pertahanan, bajet pertahanan, revolusi hal ehwal ketenteraan \& industri pertahanan serta peranan penglibatan luar ATM atau dipanggil external approach. Setiap pendekatan ini merupakan aspek penting dalam dasar pertahanan yang menerangkan secara terperinci mengenai bagaimana kesiapsediaan ATM dalam melaksanakan tanggungjawabnya untuk menjaga keamanan dan kedaulatan negara serta menjamin kepentingan negara. Oleh itu kajian ini akan menjelaskan tentang proses pemodenan serta pembangunan ATM serta juga melihat kerajaan memodenisasi ATM secara pesat seiring dengan matlamat negara untuk sentiasa membangunkan ATM.

\footnotetext{
${ }^{6}$ Kementerian Pertahanan Malaysia (2006) Laporan Tahunan Kementerian Pertahanan Malaysia

${ }^{7}$ Ananthan, S. (2017) Defence Budget And Force Modemisation Of The Malaysian Armed Forces. Centre for Defence and Intemational Security Studies (CDiSS), National Defence University Ma laysia (NDUM). No 13 hlmn 1-4

${ }^{8}$ Mohamad Sabu (2019) Tambah dana Kementerian Pertahanan. Berita Harian, maklumat diekses pada September 2019 di https://www.bharia n.com.my/berita/na sional/2019/08/596659/tambah-danakementerian-pertahanan

${ }^{9}$ Datuk Seri Mohd Johari Bahanum (2017) Aset canggih lindungi perairan negara. Berita Harian, maklumat diekses pada April 2019dihttps://www.bharian.com.my/node/270679
} 
Rajah 1: Komponen Aspek Pembangunan (ATM) di Malaysia ${ }^{10}$

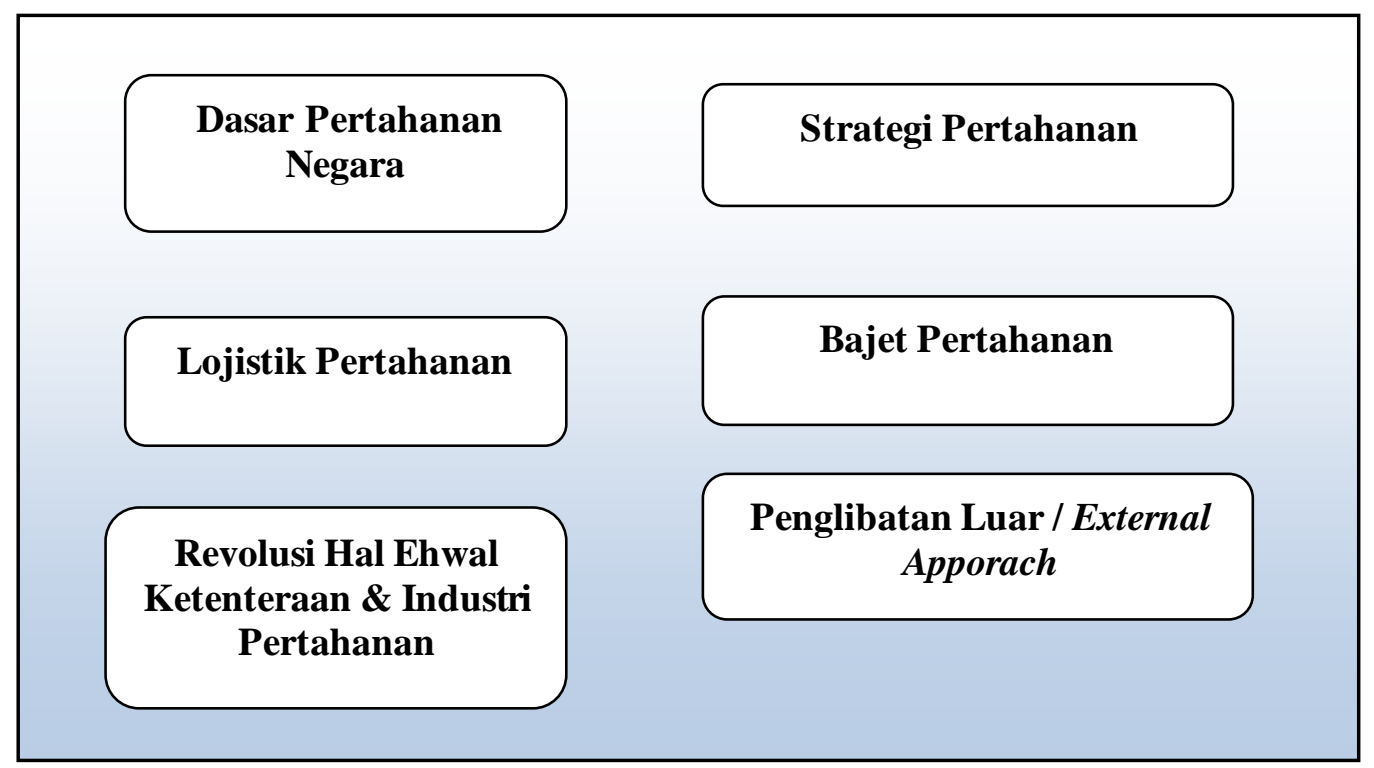

\section{Perspektif Pembangunan ATM sebelum 1990 (Era Perang Dingin)}

Melihat daripada sudut pembangunan Angkatan tentera ATM sebelum tahun 1990 iaitu semasa era Perang Dingin sebenarnya telah menunjukkan pembangunan ATM yang sangat mendatar dan tidak menunjukkan pembangunan yang sangat drastik. Perkara ini telah diutarakan oleh Abdul Razak Baginda (2009) dengan menyatakan ATM pada masa itu telah fokus kepada bagaimana untuk mengekang dan ancaman Komunis yang dibuat oleh PKM dan gerakkan untuk membasmi saki-baki PKM. ${ }^{11}$ Sebagai contoh pada zaman TAR sebagai Menteri Pertahanan, beliau telah melancarkan Dasar Keselamatan dan Pembangunan yang dikenali sebagai KESBAN dan pada era pentadbiran Tun Dr Mahatir Mohamad sebagai Menteri Pertahanan, TDM telah melancarkan dasar Keselamatan Menyeluruh yang dikenali sebagai HANRUH. ${ }^{12}$ Dapat dilihat program seperti ini memang telah berjaya membasmi dan mengekang ancaman Komunis yang telah dilancarkan oleh PKM. Namun begitu, adakah program seperti ini mampu mengekang ancaman-ancaman yang lain yang baru yang mampu menggugat ancaman keselamatan negara. Contoh ancaman lain adalah seperti ancaman bukan tradisional iaitu seperti terorisme. Dengan ini secara jelas menunjukkan pembangunan ATM sebelum tahun 1990 bersifat untuk mengekang ancaman bentuk tradisional sahaja. Keadaan ini disokong oleh sarjana seperti Abdul Razak Baginda (2009) dengan menyatakan pembangunan ATM sebelum tahun 1990 tidak fokus kepada ancaman bukan tradisional tetapi hanya fokus kepada ancaman bentuk tradisional sahaja. ${ }^{13}$

Muthiah (1990) telah menyatakan Pertahanan berdikari atau Self-Reliance yang telah diilhamkan oleh Tun Abdul Razak pada tahun 1970 adalah bertujuan untuk membangun dan memodenkan ATM secara drastik. Walaupun diilhamkan pada tahun 1970 namun usaha pembangunan yang drastik hanya dapat dilihat pada tahun 1979 apabila Tun Hussein Onn menjadi Perdana Menteri Malaysia dan juga Menteri Pertahanan pada ketika itu dengan memperkenalkan program baru yang diberi nama Program

\footnotetext{
${ }^{10}$ Sumber diambil dan diolah dari kajian tesis kajian Dr Mohamad Faisol Keling (2016). Dasar Pertahanan Negara Malaysia : Analisis Ke Atas Prinsip Pertahanan Self-Reliance. Tesis Kajian Doktor Falsafah (PhD). Kolej Undang-Undang, Kerajaan Dan Pengajian Antarabangsa, Universiti Utara Malaysia. Februari

${ }^{11}$ Abdul Razak Baginda (2009), Malaysia 's Defence \&Security Scince 1957, Malaysia Strategic Research Center, Percetakan Printpack Sdn. Bhd, Kuala Lumpur. m/s 1-30

${ }^{12}$ ibid

${ }^{13} \mathrm{ibid}$
} 
Perkembangan Istimewa Angkatan Tentera yang dikenali sebagai PERISTA. ${ }^{14}$ Dengan adanya program ini ATM pada ketika itu telah berjaya membesarkan angkatan tentera melalui tiga sektor utama iaitu Tentera Darat Malaysia (TDM), Tentera Udara Diraja Malaysia (TUDM) dan Tentera Laut Diraja Malaysia (TUDM) dengan membuat pembelian aset logistik untuk ketenteraan. Namun begitu program PERISTA ini hanya bertahan selama tiga tahun apabila TDM mengambil alih pentadbiran negara dan juga menjadi Menteri Pertahanan. Program ini terpaksa dibatalkan oleh beliau pada tahun 1983 kerana TDM melihat tidak ada ancaman dari luar khususnya Vietnam yang mahu menggugat negara serta bajet yang telah diperuntukkan untuk tujuan membangunkan program PERISTA ini digunakan untuk tujuan pembangunan ekonomi negara. Lanjutan dari ini menyebabkan pembangunan ATM secara yang asalnya mahu dibuat secara drastik tidak dapat dilaksanakan secara menyeluruh semasa era Perang Dingin. ${ }^{15}$

Satu la faktor adalah berkaitan dengan pembangunan aset-aset ketenteraan ATM. Merujuk kepada Kogila Balakrishnan (2008), beliau menyatakan bahawa pembelian aset dan peralatan ketenteraan untuk tujuan logistik ATM semasa Perang Dingin banyak memfokuskan kepada aset-aset yang mampu menghadapi peperangan hutan atau lebih dikenali sebagai 'Jungle Warefare' serta Total War. ${ }^{16}$ Hal ini dapat dilihat dengan ATM membuat pembelian aset logistik ketenteraan seperti Radpanzer Condor, Scorpion/Stormer, Sibmas, untuk memenuhi Logistik ATM yang mampu menghadai peperangan di hutan, manakala F-5 Fighter Aircraft, PC-7 Trainer Aircraft, MB-339A Trainer Aircraft, A-4PTM Fighter Aircraft untuk memenuhi aset logistik TUDM bagi menghadapi Total War. Manakala aset-aset seperti Sri Indera-class support ship, Kasturi-class corvette dan Lerici-class mine counter ship adalah untuk tujuan membangunkan aset-aset TLDM. Dilihat kepada pembelian aset-aset ketenteraan ini jelas sekali semasa Perang Dingin modus operandi pembangunan ATM memfokuskan kepada keupayaan membanteras ancaman subversif dari PKM dan jelas ATM pada masa itu kurang memberikan penekanan kepada ancaman selain konvensional (Total War).

Merujuk kepada M. Haniff (2008), satu lagi perkara yang mengekang usaha untuk membangunkan ATM secara pesat adalah kerana keadaan aset logistik tersebut. beliau ada menyatakan bahawa pembelian aset ketenteraan ATM semasa era Perang Dingin banyak memfokuskan kepada aset-aset terpakai. Aset logistik yang terpakai arau Secondhand ini adalah sangat berisiko tinggi. Dalam aspek Logistik Pembelian aset-aset ketenteraan yang telah digunakan (Secondhand) ini adalah sangat berisiko tinggi untuk rosak dan menghadapi masalah. ${ }^{17}$ Sebagai contoh pada 1988, negara Malaysia telah membuat pembelian terbesar aset untuk kegunaan TUDM iaitu sebanyak 88 unit pesawat pejuang jenis Skyhawk. Pembelian kelengkapan ini merupakan aset-aset yang terpakai untuk tujuan pertahanan. Pembelian aset pertahanan ini adalah lebih dipengaruhi oleh harga dan tidak berkualiti. Menurut Fazli Arman (1993) menyatakan "pembelian kurang berkualiti dapat dilihat melalui pembelian pesawat A4 Skyhawk yang merupakan pesawat terpakai "secondhand" daripada AS pada tahun 1988 dengan 88 buah pesawat A4PTM (Skyhawk) adalah pembelian terbesar ATM dalam sejarah mendapatkan pesawat pejuang yang hanya mampu beroperasi 6 tahun."

Menurut Ehsan (2008), beliau menyatakan faktor lain seperti pembangunan industri pertahanan (Defense Industri) yang dilihat mula pada penghujung tahun 1960an dengan penubuhan Syarikat Malaysia Explosives Sdn Bhd pada tahun 1969 adalah bertujuan untuk merancakkan lagi kepesatan pembangunan ATM. Ia dilihat sangat signifikan dengan pada tahun 1970, Tun Abdul Razak telah melaksanakan konsep pertahanan berdikari sebagai struktur yang asas untuk pembangunan ATM. Hasil daripada struktur ini Defence Research Center' (DRC) diwujudkan sebagai pembukaan kepada

\footnotetext{
${ }^{14}$ Muthiah Alagappa (1990), Malaysia: From The Commonwealth to Self-Reliance sumber disunting dari Chin Kin Wah (1990) Defence Spending In Southeast Asia, Institute of Southeast Asian Studies, Singa pore m/s 181-193.

${ }^{15}$ Danny Liew Shan Lee (2007) . Dasar Pertahanan Negara: Pandangan Sekilas Lalu . Majalah Perajurit 2007

${ }^{16}$ Kogila Balakhrishnan (2008) Defence Industrialisation in Malaysia Development Challenges and the Revolution inMilitary Affairs. Security Challenges, Vol. 4, No. 4 (Summer 2008), pp. 135-155

${ }^{17}$ M. Haniff Ismail (2008) Pembelian Aset Terpakai Satu Pandangan. Majalah Perajurt, Julai. ms 14-19
} 
ATM untuk menceburi bidang Industri Pertahanan pada tahun 1972. ${ }^{18}$ Namun setelah tamatnya Perang Dingin pada tahun 1990 iaitu hampir 21 tahun yang selepas. Dilihat kewujudan penubuhan Syarikat Malaysia Explosives Sdn Bhd ini untuk membangunkan industri pertahanan atau penyelidikan R\&D untuk ATM mencipta teknologi atau kajian untuk pertahanan, masih tidak fokus kepada kehendak pembangunan pertahanan secara menyeluruh dan dilihat keberkesanan menubuhkan DRC juga masih samar-samar dan tidak dapat memenuhi kehendak hasrat Tun Abdul Razak untuk membangunkan industri pertahanan negara secara drastik ke arah pertahanan berdikari. ${ }^{19}$

\section{Perspektif Pembangunan ATM Pasca Perang Dingin}

Pembangunan ATM dilihat amat drastik pada pasca Perang Dingin dengan memperlihatkan pembangunan ATM ke arah untuk mewujudkan pemodenan angkatan tentera. Menurut Kogila (2008), beliau menyatakan negara Malaysia memulakan pemodenan tentera secara berskala besar dan juga membuat peningkatan teknologi sejak dari awal tahun 1990an. ${ }^{20}$ Menurut juga sarjana-sarjana yang lain seperti S Jayasankaran (2002), Jaswan (2009) dan Abdul Razak Baginda (2009), ini dapat merumuskan secara keseluruhan bahawa modenisasi pembangunan dan pertahanan ATM dilihat telah melengkapi pembangunan ATM di ketiga-tiga unit iaitu TUDM, TLDM dan TTDM pada pasca Perang Dingin. Keadaan ini dapat dilihat dengan pembelian aset-aset yang baru dari negara kuasa besar seperti negara Britain, negara Amerika Syarikat dan negara Rusia dengan aset-aset yang dibeli adalah seperti jet pejuang dan helikopter seperti $F / A-18 s, C-130 s, F-5 s, A-4 s$ serta $H-3$. Kerajaan Malaysia juga membuat pembelian 18 unit jet pejuang $M I G-29$ Fighter. ${ }^{21}$ Pembelian yang lain adalah seperti Jet pejuang seperti HAWK MK108, pesawat sukhoi SU30MKM dari negara Rusia, kereta kebal ADNAN armoured combat vehicles, PT-91m, kapal selam Scorpene dari negara Perancis, Astros II dari negara Brazil dan G5 MKIII peluru berpandu jarak dekat, senjata Styer Sniper serta beberapa unit Kapal Perang Tempur. ${ }^{22}$ Secara keseluruhannya dapat dilihat bahawa ATM telah diberi nafas baru semasa dalam pentadbiran Dato Sri Najib Tun Razak (DSN) semasa beliau diberi mandat untuk menjawat jawatan Menteri Pertahanan. Beliau dilihat telah mula melaksanakan pembangunan ATM secara drastik ke arah pertahanan berdikari. Jika dilihat dengan rekod beliau dilantik selama dua kali (tahun1990-1995 dan tahun 1999-2008) banyak perubahan yang telah beliau laksanakan bertujuan membangunkan serta memodenkan ATM ke tahap yang lebih baik. Namun ia juga dilihat masih tidak cukup untuk melabelkan ATM pada hari ini telah dimodenkan dan dibangunkan secara drastik kerana masih terdapat lagi lompang-lompang yang terpaksa dibaiki oleh ATM.

Malaysia juga turut membuat pembelian aset-aset moden dan canggih Ketika zaman pentadbiran DSN sebagai Menteri Pertahanan. Menurut Khairil (2016), kerajaan Malaysia telah melaksanakan pemodenan ATM melalui peningkatan keupayaan pemerolehan dan latihan Strategik Sejak DSN mula mengambil alih Kementerian Pertahanan pada tahun 1990. ${ }^{23}$ Aset-aset canggih telah mula diperkenalkan antaranya adalah seperti pesawat canggih Sukhoi, MiG-29N, jet pejuang yang canggih F/A-18D Hornet dan jet latihan lanjutan $M B-339 C$ serta pesawat pengangkut tercanggih yang diperoleh pada tahun 2005 iaitu pesawat jenis $A 400 M$ untuk memantapkan lagi sistem pertahanan udara $^{24}$ dan pesawat latihan asas iaitu Platus PC-7 MkII siri 7. ${ }^{25}$ Dari pembelian aset-aset yang canggih dari sudut pertahanan Tentera Darat segi aset bagi pertahanan darat pula adalah seperti kerajaan membuat pembelian sistem starbust dan kemudian digantikan dengan sistem yang canggih iaitu sistem Igla dan sistem Jernas, kereta kebal utama yang dinamakan "Pendekar" yang merupakan aset yang

\footnotetext{
${ }^{18}$ Ehsan Iskandar (2008). STRIDE: 40 Tahun Memacu Penyelidikan Pertahanan Negara. Perajurit. Mei. Muka 45-49

${ }^{19} \mathrm{ibid}$

${ }^{20}$ Kogila Balakrishnan (2008). Op.cit m/s 135-155

${ }^{21}$ Abdul Razak Baginda (2009). Op.cit m/s 24-27

${ }^{22} \mathrm{ibid}$

${ }^{23}$ Khairil Annas Jusih (2016) Najib Razak Berjiwa Besar: Empat Dekad Menongkah Arus Kepimpinan \& Politik. Ya yasan Penyelidikan Transformasi

${ }^{24}$ Andrew T. H. Tan (2014) The Global Arms Trade. A Handbook, Routledge Taylor \& Francis Group, New York, USA. ms. 23-24

${ }^{25}$ Platus PC-7 MKII (2008). da lammajalah Perajurit, Kuala Lumpur, Januari
} 
diubahsuai dari model kenderaan PT-91M, kereta perisai ACV-300s ADNAN. ATM juga membuat pembelian (MLRS) Astros yang merupakan sistem pelancar roket berganda yang canggih serta sistem peluru berpandu anti kereta kebal yang canggih seperti Metis M dan Baktar-Shikan. Dalam memantapkan lagi sektor pertahanan lautan pula untuk TLDM, ATM telah membeli dan menjadi perintis kepada Kapal ronda generasi baru seperti (NGPV), Frigate kelas jebat dan Kapal Korvet Kelas Kasturi, kapal LCS (Littoral Combatant Ship) serta buat pertama kali negara memiliki 2 unit kapal selam Kapal Selam Scorpene yang dibeli dari negara Perancis untuk kegunaan pertahanan lautan ${ }^{26}$

Untuk terus mengembangkan dan pembangunan sektor industri pertahanan negara, sebuah institusi penyelidikan Industri Pertahanan diwujudkan yang diberi nama Institut Penyelidikan Sains dan Teknologi Pertahanan (STRIDE). STRIDE ditubuhkan pada tahun 2012 untuk melaksanakan bantuan sains dan teknologi dalam R\&D untuk tujuan pembangunan pertahanan, penilaian, perolehan dan penggunaan perkakasan serta sistem pertahanan negara. STRIDE juga menyediakan sumber-sumber saintifik dan teknologi yang bertepatan dengan kehendak pertahanan negara dalam membentuk hubungan industri dengan tujuan memberi bantuan saintifik dan teknologi kepada pembangunan industri pertahanan tempatan. Keadaan ini dapat mewujudkan hubungan teknikal bersama organisasi penyelidikan luar untuk tujuan meningkatkan keupayaan saintifik dan juga teknologi pertahanan. ${ }^{27}$ ATM juga dilihat telah menggunakan sepenuhnya program-program pameran yang sedia ada seperti Program Defence Services Asia (DSA) serta Langkawi International Maritime and Aerospace Exhibition (LIMA) bagi sebagai tempat untuk membuat pembelian aset-aset pertahanan dan pembangunan keupayaan ATM. ${ }^{28}$

Dalam pada itu dari segi pembangunan dasar serta pertahanan pula ATM telah mewujudkan Dasar Pertahanan Negara 2010 (DPN) dan DPN ini pada awalnya boleh dikatakan sebagai "Defence White Paper" ATM kerana dari tahun 1957 sehingga tahun 2010 sebelum penubuhan DPN, negara masih lagi belum mempunyai 'Buku Putih Pertahanan' yang menggariskan prinsip-prinsip pertahanan negara.

"The involment and expansion of the national service programme will depend on national needs, its success in achieving its goals and public perception. We have established a mechanism to continuously monitor and recommend changes to improve the national service. "29

Pembangunan dan pemodenan ATM bukan hanya menyentuh kepada pembelian aset-aset ketenteraan semata-mata, akan tetapi rakyat juga perlu diberikan penghayatan dari sudut pemahaman dasar dan juga perlu dilibatkan dalam dasar pertahanan yang telah dibangunkan oleh ATM seperti dasar HANRUH. menurut Vishalache (2013), di dalam membentuk masyarakat Malaysia dan memberi pendedahan kepada rakyat Malaysia untuk memahami dasar HANRUH, konsep Program Latihan Khidmat Negara (PLKN) ini mula dijalankan pada 16 Feb 2004. Menurut beliau lagi:

"Program ini juga sebenarnya turut memberi pendedahan yang baik kepada remaja-remaja khususnya orang awam bertujuan untuk meningkatkan pengetahuan, semangat cintakan negara dan sanggup berkorban untuk negara. Pelatih PLKN juga didedahkan dengan kehidupan survival di hutan dan melatih mereka perkara asas di dalam ketenteraan seperti berkawad, latihan asas ketenteraan dengan menggunakan senjata api seperti senapang M16. "30

"Adalah menjadi hasrat untuk memperlengkapkan diri Warga ATM dengan ilmu dan latihan ketenteraan. Perolehan aset yang canggih tanpa mempunyai warga

\footnotetext{
${ }^{26} \mathrm{ibid}$

${ }^{27}$ Ehsan Iskandar (2008). Op.cit ms. 45-46

${ }^{28}$ Malaysia To Upgrade Military Assets to strengthen defence, Malaysia Outlook, 21 Mei 2017. http://www.malaysiaoutlook.com/malaysia-to-upgrade-military-assets-to-strengthen-defence-pm-najib/

${ }^{29}$ (2008) Temuramah eksklusifbersama Da to' Sri Mohd Najib Tun Abdul Razak. Op.cit ms. 2 -5

${ }^{30}$ Visha lache Balakrishnan (2013) Penilaian Program Latihan Khidmat Negara Dari Perspertif Pelatih:

Satu Kajian Kes. Asia Pacific Journal of Educators, Vol28, 69-80
} 
yang mempunyai pengetahuan, kompeten dan bersikap positif tidak akan menjamin keberkesanan dan keupayaan yang dihasratkan daripada aset-aset tersebut. Usaha bagi meningkatkan tahap akademik anggota malah merupakan usaha ATM untuk menyediakan anggota untuk menghadapi sebarang situasi di masa hadapan. "31

Dalam memperkukuhkan lagi ilmu pertahanan, kerajaan juga komited untuk menubuhkan sebuah institusi akademik untuk pendidikan pertahanan negara. Hasrat negara serta ATM adalah institusi ini dapat digunakan untuk meningkatkan lagi tahap akademik anggota ATM supaya menjadi lebih berpengetahuan dan berdaya saing tercapai dengan wujudnya Akademi Tentera Malaysia ATMA dan kemudian akademi ini dinaiktarafkan untuk menjadi Universiti Pertahanan Nasional Malaysia (UPNM). Ini merupakan salah satu usaha yang berkesan yang telah dilaksanakan oleh kerajaan untuk membangunkan sektor pendidikan serta ilmu pertahanan kepada ATM. Usaha ATM adalah ke arah menyediakan anggota ATM yang berkualiti patut diberi pujian kerana pembangunan pertahanan bukan sahaja meliputi pembelian aset-aset ketenteraan tetapi juga meliputi pendidikan dan modal insan.

Secara kesimpulan dilihat ATM sememangnya telah mula melaksanakan transformasi dan pembangunan ATM serta dilihat pada pasca Perang dingin pemodenan ATM dapat dilihat dan menjadikan ATM lebih dinamik dan seiring dengan peredaran zaman. Oleh yang demikian masih lagi terdapat beberapa faktor juga perlu dilihat seperti perolehan bajet pertahanan dan juga penglibatan luar yang juga mampu menyumbang kepada pembangunan ketenteraan yang drastik ini. Namun ia juga dilihat modenisasi ATM masih tidak cukup untuk melabelkan ATM pada hari ini telah dimodenkan dan dibangunkan secara drastik kerana masih terdapat lagi lompang-lompang yang terpaksa dibaiki oleh ATM

\section{Kesimpulan}

Berdasarkan kajian yang telah dilakukan ke atas konsep kajian latar belakang kerangka teori, keadaan ini telah memperlihatkan bertapa pentingnya teori realisme dalam menganalisakan tentang kenapa sesebuah negara itu perlu memberi tumpuan didalam membangunkan dan memodenkan ATM kepada tahap yang lebih baik. konsep yang realisme menekankan kepada keutamaan negara untuk saling bergantung kepada diri sendiri (self reliance) dalam aspek keselamatan bagi menjaga kepentingan negara. Ia adalah disebabkan negara kini telah dipengaruhi oleh keadaan sistem antarabangsa yang seperti tiada undang-undang dan bersifat anarki dan sifat sesebuah negara adalah sentiasa mahu terus bersaing di antara satu sama yang lain. ${ }^{32}$ "Fenomena anarki" telah mempengaruhi kebanyakan negara untuk memberikan tumpuan dan perhatian terhadap pembangunan Angkatan ketenteraan bagi menjamin keselamatan untuk tujuan kelangsungan hidup. Manakala merujukkan kepada teori neorealisme, teori ini mengatakan dilema keselamatan sebagai situasi yang sentiasa ada ancaman yang cuba untuk menggugat keselamatan negara mahupun ia dari bentuk unsur ancaman tradisional mahupun dari unsur dari ancaman bukan dari tradisional. Akibat dari senario keselamatan dan sifat anarki dalam sistem antarabangsa, keadaan ini akan menyebabkan negara perlu bergantung pada diri sendiri untuk kelangsungan hidup. Ini merujuk kepada konsep self help atau self reliance di mana setiap negara mempunyai kepentingan negara mereka tersendiri dalam meneruskan kelangsungan hidup dalam sistem antarabangsa. ${ }^{33}$

Bagi teori kepentingan nasional pula, teori ini menerangkan tentang bagaimana pentingnya sesebuah wilayah dan persempadanan (teritorial). Ia merupakan aset yang penting bagi sesebuah negara. Negara (State) sentiasa memerlukan penggunaan segala kuasa (Power) yang ada dengan apa cara sekalipun agar kedaulatan sesebuah negara (Soveringnity) akan sentiasa terbela dan terjamin. ${ }^{34}$ Dalam menceritakan mengenai pembangunan serta permodenan ATM, aplikasi teori pembangunan pertahanan (Military Development Theory) adalah perlu bagi menerangkan tahap pembangunan serta

\footnotetext{
${ }^{31}$ Dato' Sri Mohd Najib Tun Abdul Ra zak(2006). Op.cit.

${ }^{32}$ Kogila Balakrishnan(2008). Op.cit m/s 135-155

${ }^{33}$ Muthiah Alagappa (1990). Op.cit m/s 186

${ }^{34}$ John Paxton (1972) The Stateman's Year-Book. Statistical and Historical Annual of The States of The

Year 1972-1973, Macmillan St Martin's Press, New York
} 
tahap pemodenan sesebuah angkatan tentera. Sebagai contoh teori ini menerangkan tentang bertapa pentingnya sesebuah negara untuk membangunkan angkatan tenteranya melalui sudut pembangunan dasar pertahanan, dari sudut aspek bajet ketenteraan serta pembangunan strategi pertahanan agar ia akan sentiasa menjadi relevan dalam mengekang segala bentuk ancaman konvensional serta strategik. Manakala teori revolusi hal-ehwal ketenteraan (Revolution in Military Affairs (RMA)) pula banyak menekankan tentang perlunya revolusi dilaksanakan dalam aspek pembangunan logistik dan pertahanan dengan kerajaan perlu membuat pembelian aset-aset logistik yang baru yang canggih dan moden atau dapat mewujudkan penghasilan produk-produk pertahanan dan membuat penyelenggaraan melalui hasil daripada pembangunan industri pertahanan (Defense Industry) negara. ${ }^{35}$

ATM juga perlu mengaplikasikan unsur balance of Power (BoP) sebagai satu elemen yang penting di dalam membuat perhubungan antarabangsa. ATM juga dilihat perlu melaksanakan pendekatan kepentingan luaran dengan memfokuskan kepada sudut kerjasama pertahanan, penggubalan dasar luar serta juga melibatkan diri dalam organisasi antarabangsa yang penting seperti Pertubuhan BangsaBangsa bersatu (PBB) ${ }^{36}$ Kerjasama seperti latihan ketenteraan bersama dengan perjanjian pertahanan Five Power Defense Agreement (FPDA), ${ }^{37}$ juga penglibatan Malaysia dalam misi pengaman PBB serta peranan yang penting negara dalam pertubuhan rantau ASEAN dan ASEAN Regional Forum (ARF) akan memperlihatkan lagi kehebatan negara serta negara juga akan mendapat banyak manfaat seperti ilmu pertahanan, pemindahan teknologi pertahanan yang akan membantu kepada pembangunan dan pemodenan ATM. ${ }^{38}$ Keadaan ini juga sedikit sebanyak akan mewujudkan keseimbangan kuasa melalui pakatan pertahanan yang boleh dibentuk (alliance). Keseimbangan kuasa adalah suatu perkara yang perlu diwujudkan agar negara tidak sentiasa di buli dan dipermainkan oleh kuasa-kuasa besar dunia. Perspektif Pembangunan dan pemodenan ATM sebelum dan selepas Perang Dingin ternyata mempunyai perubahan yang signifikan di mana pembangunan ATM sebelum tahun 1990 lebih bersifat konvensional dan pasca Perang Dingin pembangunan ATM bersifat lebih strategik dengan memperlihatkan pemodenan ATM yang dilaksanakan dari pelbagai sudut.

\section{Rujukan}

Abdul Razak Baginda (2009), Malaysia's Defence \&Security Scince 1957, Malaysia Strategic Research Center, Percetakan Printpack Sdn. Bhd, Kuala Lumpur.

Ananthan, S. (2017) Defence Budget And Force Modernisation Of The Malaysian Armed Forces. Centre for Defence and International Security Studies (CDiSS), National Defence University Malaysia (NDUM).

Andrew T. H. Tan (2014) The Global Arms Trade. A Handbook, Routledge Taylor \& Francis Group, New York, USA.

Danny Liew Shan Lee (2007) . Dasar Pertahanan Negara: Pandangan Sekilas Lalu. Majalah Perajurit 2007

Datuk Seri Mohd Johari Baharum (2017) Aset canggih lindungi perairan negara. Berita Harian, maklumat diekses pada April 2019 di https://www.bharian.com.my/node/270679

Dato' Sri Mohd Najib Tun Abdul Razak (2006). semasa ucapan Penggulungan Bajet 2007 di Peringkat Dasar di Dewan Rakyat. http://www.pmo.gov.my/ucapan/?m=p\&p=najibtpm\&id=3587

Dr Mohamad Faisol Keling (2016). Dasar Pertahanan Negara Malaysia : Analisis Ke Atas Prinsip Pertahanan Self-Reliance. Tesis Kajian Doktor Falsafah (PhD). Kolej Undang-Undang, Kerajaan Dan Pengajian Antarabangsa, Universiti Utara Malaysia. Februari

Ehsan Iskandar (2008). STRIDE: 40 Tahun Memacu Penyelidikan Pertahanan Negara. Perajurit.

\footnotetext{
${ }^{35}$ Roxborough, Ian. (2002) "From revolution to transformation: the state of the field - Military Transformation." Joint Force Quarterly 32 (Autumn).

${ }^{36} \mathrm{He}$, Ka i. (2008). Institutional Balancing and International Relations Theory: Economic Interdependence and Balance of Power Strategies in Southeast Asia. European Jou rnal of International Rela tions -EUR J INT RELAT. 14.489-518. 10.1177/1354066108092310.

${ }^{37}$ J.M.Jamaluddin (2006) FPDA Expanding its Role Beyond Security Concerns, Asian Defence Journal(ADJ), July \&Aug muka 6-7.

${ }^{38}$ Mohd Yahya Mohamed Ariffin (2007) Pedekatan Dasar Luar, Sumber disunting dari Utusan Malaysia bertarikh 19 Nov 2007.
} 
He, Kai. (2008). Institutional Balancing and International Relations Theory: Economic Interdependence and Balance of Power Strategies in Southeast Asia. European Journal of International Relations, 14, 489-518. 10.1177/1354066108092310.

J.M.Jamaluddin (2006) FPDA Expanding its Role Beyond Security Concerns. Asian Defence Journal(ADJ), 6-7.

John Paxton (1972) The Stateman's Year-Book. Statistical and Historical Annual of The States of The Year 1972-1973, Macmillan St Martin's Press, New York.

Keling, M. F., Mohamad, M. H., \& Abdul Batau, M. F. (2016). Faktor dan Proses Pembangunan Dasar Pertahanan Negara Malaysia. Malaysian Journal of Social Sciences and Humanities (MJSSH), 1(3), 31 - 41. Retrieved from https://msocialsciences.com/index.php/mjssh/article/view/16

Kementerian Pertahanan Malaysia (2006) Laporan Tahunan Kementerian Pertahanan Malaysia

Khairil Annas Jusih (2016) Najib Razak Berjiwa Besar: Empat Dekad Menongkah Arus Kepimpinan \& Politik. Yayasan Penyelidikan Transformasi

Kogila Balakhrishnan (2008) Defence Industrialisation in Malaysia Development Challenges and the Revolution inMilitary Affairs. Security Challenges, 4(4), 135-155

M. Haniff Ismail (2008) Pembelian Aset Terpakai Satu Pandangan. Majalah Perajurt, Julai. ms 14-19

Malaysia To Upgrade Military Assets to strengthen defence, Malaysia Outlook, 21 Mei 2017. http://www.malaysiaoutlook.com/malaysia-to-upgrade-military-assets-to-strengthen-defence-pmnajib/

Mohamad Sabu (2019) Tambah dana Kementerian Pertahanan. Berita Harian, maklumat diekses pada September 2019 di https://www.bharian.com.my/berita/nasional/2019/08/596659/tambah-danakementerian-pertahanan

Mohd Yahya Mohamed Ariffin (2007) Pedekatan Dasar Luar, Sumber disunting dari Utusan Malaysia bertarikh 19 Nov 2007.

Muthiah Alagappa (1990), Malaysia: From The Commonwealth to Self-Reliance sumber disunting dari Chin Kin Wah (1990) Defence Spending In Southeast Asia, Institute of Southeast Asian Studies, Singapore m/s 181-193.

Noraini Zulkifli (2016), Kepentingan Nasional Jepun Di Selat Melaka: Kerangka Teori Dan Konseptual. Sumber diekses dari https://www.researchgate.net/publication/326987998_Teori_Realisme_dan_Neo_Realismepdf

Platus PC-7 MKII (2008). dalam majalah Perajurit, Kuala Lumpur, Januari

Roxborough, Ian. (2002). From revolution to transformation: the state of the field - Military Transformation. Joint Force Quarterly, 32.

Vishalache Balakrishnan (2013) Penilaian Program Latihan Khidmat Negara Dari Perspertif Pelatih: Satu Kajian Kes. Asia Pacific Journal of Educators, 28, 69-80. 